\title{
SURVIVAL LIFE PENDERITA KANKER PAYUDARA PADA WANITA BERDASARKAN GRADING \& KEMOTERAPI DI RSUD Dr. H. ABDUL MOELOEK PROVINSI LAMPUNG
}

\author{
Alya Rahmawati Suganda', Wien Wiratmoko², Esteria Marhayuni ${ }^{3}$, \\ Yuniastini ${ }^{4}$
}

\author{
${ }^{1}$ Program Studi Kedokteran Fakultas Kedokteran Universitas Malahayati \\ ${ }^{2}$ Departemen Patologi Anatomi Fakultas Kedokteran Universitas Malahayati \\ ${ }^{3}$ Departemen Parasitologi Fakultas Kedokteran Universitas Malahayati \\ ${ }^{4}$ Fakultas Kesehatan Masyarakat Universitas Malahayati
}

[email Korespondensi : alyars84@gmail.com]

\begin{abstract}
Survival Life of Breast Cancer Patients Women Based on Grading \& Chemotherapy in Dr. H. Abdul Moeloek Hospital Lampung Province. In Indonesia, breast cancer is a disease with the highest percentage of new cases with a percentage of 16.7 and cases of death with a percentage of $11.0 \%$. occupies the first position in cases of cancer death in women grading and chemotherapy is a factor that affects survival in breast cancer sufferers. This study was aim to determine the proportion of survival of women with breast cancer in women based on grading and chemotherapy in the hospital of Dr. H. Abdul Moeloek, Lampung Province, 2015-2019. The type of this research was observational with a retrospective approach. The total population was 72 and the sample was 48 . The data were analyzed using survival analysis using the Kapplan-meier method. Grading of breast cancer patients at Dr. H. Abdul Moeloek hospital, Lampung Province, the highest was in grade $3(54.2 \%)$ and the lowest was in grade 1 $(8.3 \%)$. Cancer patients who underwent chemotherapy $(72.9 \%)$ and who did not undergo chemotherapy $(27.1 \%)$. Survival life for 5 years in patients with grade 1 is $100 \%$, grade 2 is $89 \%$, and grade 3 is $20 \%$. Survival life for 5 years with chemotherapy is $65 \%$. Based on grading, 5 -year life survival was higher in grade 1 based on chemotherapy. Survival for 5 years was higher in the chemotherapy group.
\end{abstract}

Keywords: Grading, Breast cancer, Chemotherapy, Survival Life

\begin{abstract}
Abstrak: Survival Life Penderita Kanker Payudara Pada Wanita Berdasarkan Grading \& Kemoterapi di RSUD Dr. H. Abdul Moeloek Provinsi Lampung. Di Indonesia kanker payudara merupakan penyakit dengan persentase kasus baru yang paling tinggi dengan persentase $16.7 \%$ dan kasus kematian dengan persentase $11.0 \%$ menempati posisi pertama pada kasus kematian akibat kanker pada wanita Grading dan kemoterapi merupakan faktor yang mempengaruhi kelangsungan hidup pada penderita kanker payudara. Penelitian ini bertujuan untuk mengetahui proporsi kelangsungan hidup (survival life) wanita penderita kanker payudara pada wanita berdasarkan grading dan kemoterapi di RSUD. DR. H. Abdul Moeloek Provinsi Lampung tahun 2015-2019. Jenis penelitian yang digunakan adalah observasional dengan pendekatan retrospektif. Jumlah populasi 72 dan sampel 48. Data dianalisis menggunakan analisis survival metode Kaplan Meier. Grading pada penderita kanker payudara di RSUD Dr. H.Abdul Moeloek Provinsi Lampung terbanyak pada grade $3(54.2 \%)$ dan terendah pada grade $1(8.3 \%)$. Penderita kanker yang menjalani kemoterapi $(72.9 \%)$ dan yang tidak menjalani kemoterapi (27.1). Survival life selama 5 tahun penderita grade 1 adalah $100 \%$, grade 2 adalah $89 \%$, dan grade 3 adalah $20 \%$. Survival life selama 5 tahun kelompok melakukan kemoterapi kelangsungan hidupnya adalah $65 \%$. Berdasarkan grading, survival life selama 5 tahun lebih tinggi pada grade 1 Berdasarkan kemoterapi Survival life selama 5 tahun lebih tinggi pada kelompok yang menjalankan kemoterapi.
\end{abstract}

Kata Kunci: Grading, Kanker payudara, Kemoterapi, Survival Life 


\section{PENDAHULUAN}

Kanker payudara menunjukkan kasus kanker yang paling umum terjadi. $\mathrm{Di}$ Indonesia kanker payudara merupakan penyakit dengan insidensi $16.7 \%$ dan menempati posisi pertama pada kasus kematian dengan persentase $11.0 \%$. Pada wanita dengan kasus kanker payudara memiliki persentase $30.9 \%$ dengan jumlah 58.256 dari total kasus 348.809 dan total kasus kematian 207.210 (World Health Organization, 2020). Kemenkes RI pada tahun 2018, menyatakan bahwa di Pulau Sumatera termasuk angka kejadian tinggi pada kanker payudara. Di Provinsi Lampung sendiri menurut data RISKESDAS 2018 kanker payudara Indonesia di Provinsi Lampung sebanyak 1.40/1000 penduduk (Penelitian dan Pengembangan Kesehatan Kementerian Kesehatan RI, 2018). Grading merupakan salah satu faktor penting dalam menentukan pengobatan dan survival life. Grading yang dilihat dari histologi dibagi tiga yaitu, grade I berdiferensiasi baik/rendah, grade II berdiferensiasi sedang, dan grade III berdiferensiasi buruk/berat (Canadian Breast Cancer, 2020).

Selain grading, kemoterapi ikut berpengaruh dalam kualitas dan kuantitas hidup. Juwita, dkk (2018) menyatakan bahwa, Penderita kanker payudara dengan kemoterapi adjuvan memiliki kualitas hidup lebih baik pada setiap skala dibandingkan dengan kemoterapi neoadjuvan. respon yang baik dan dapat meningkatkan kelangsungsungan hidup penderita (Juwita dkk, 2018).

\section{METODE}

Penelitian ini adalah penelitian observasional dengan rancangan retrospektif. Menggunakan teknik purposive sampling. Pengumpulan data menggunakan rekam medik dan wawancara per telepon. Populasi penelitian adalah penderita kanker payudara yang terdiagnosa tahun 2015 berjumlah 72 kasus. Setelah ditelusuri didapat 48 kasus yang memiliki rekam medik sesuai dengan kriteria penelitian. Data dianalisis dengan analisis survival life metode Kaplan-meier. Waktu pengamatan 2015 - 2019.

\section{HASIL}

\section{Grading}

Tabel 1. Distribusi Frekuensi Grading Penderita Wanita Kanker Payudara Saat Pertama Didiagnosa Tahun 2015 di RSUD Dr. H. Abdul Moeloek

\begin{tabular}{ccc} 
Saat Pertama Didiagnosa Tahun & $\mathbf{2 0 1 5}$ di RSUD Dr. H. Abdul Moeloek \\
\hline Grading & Frekuensi & \% \\
\hline Grade 3 & 26 & 54.2 \\
Grade 2 & 18 & 37.5 \\
Grade 1 & 4 & 8.3 \\
\hline Total & $\mathbf{4 8}$ & $\mathbf{1 0 0}$ \\
\hline
\end{tabular}

Tabel 1 menunjukan, dari 48 penderita kanker payudara yang diteliti, grade tertinggi adalah grade 3 terdapat 28 penderita $(54.2 \%)$, kemudian pada grade 2 terdapat 16 penderita $(37.5 \%)$ dan yang terendah terdapat pada grade 1 dengan jumlah 4 penderita $(8.3 \%)$. 


\section{Kemoterapi}

Tabel 2. Distribusi Frekuensi Wanita Penderita Kanker Payudara

Berdasarkan Kemoterapi Yang Terdiagnosa Tahun 2015 di RSUD Dr. H. Abdul Moeloek

\begin{tabular}{ccc}
\hline Kemoterapi & Frekuensi & Persentase (\%) \\
\hline Tidak Kemoterapi & 13 & $27.1 \%$ \\
Kemoterapi & 35 & $72.9 \%$ \\
\hline Total & $\mathbf{4 8}$ & $\mathbf{1 0 0 \%}$ \\
\hline
\end{tabular}

Berdasarkan tabel 2, dari 48 penderita kanker payudara terdapat 35 penderita menjalani kemoterapi

(72.9\%) dan 13 penderita tidak menjalani kemoterapi $(27.1 \%)$.

\section{Status Kejadian}

Tabel 3. Distribusi Status Kejadian Penderita Kanker Payudara Tahun 20152019 di RSUD. Dr. H. Abdul Moeloek

\begin{tabular}{|c|c|c|c|c|c|c|c|c|}
\hline \multirow{2}{*}{$\begin{array}{c}\text { Survival } \\
\text { Life }\end{array}$} & \multicolumn{8}{|c|}{ Frekuensi Status Kejadian } \\
\hline & Meninggal & $\%$ & Hilang & $\%$ & Hidup & $\%$ & Jumlah & $\%$ \\
\hline $\begin{array}{c}\text { Tahun } \\
\text { ke } 1\end{array}$ & 0 & 0 & 5 & 10.4 & 43 & 89.6 & 48 & 100 \\
\hline $\begin{array}{c}\text { Tahun } \\
\text { ke } 2\end{array}$ & 1 & 2.3 & 17 & 39.5 & 25 & 58.1 & 43 & 100 \\
\hline $\begin{array}{c}\text { Tahun } \\
\text { ke } 3\end{array}$ & 2 & 8 & 4 & 16 & 19 & 76 & 25 & 100 \\
\hline $\begin{array}{c}\text { Tahun } \\
\text { ke } 4\end{array}$ & 7 & 36.8 & 3 & 16 & 9 & 47.4 & 19 & 100 \\
\hline $\begin{array}{c}\text { Tahun } \\
\text { ke } 5\end{array}$ & 0 & 0 & 2 & 22.2 & 7 & 77.8 & 9 & 100 \\
\hline Total & 10 & 20.8 & 31 & 64.6 & 7 & 14.6 & & \\
\hline
\end{tabular}

Pada tabel 3, menunjukkan distribusi frekuensi penderita kanker payudara di RSUD Dr. H Abdul Moeloek berdasarkan status kejadian. Dari 48 penderita yang diteliti, pada tahun ke 1 tidak ada yang dinyatakan meninggal (event) dan 5 penderita (10.4\%) dinyatakan hilang dari pengamatan.

Pada tahun ke 2 terdapat 1 penderita (2.3\%) meninggal (event) dan 17 penderita (39.5\%) dinyatakan hilang dari pengamatan. Pada tahun ke 3 terdapat 2 penderita ( $8 \%$ ) dinyatakan meninggal (event) dan 4 penderita $(16 \%)$ dinyatakan hilang dari pengamatan. Pada tahun ke 4 terdapat
7 penderita (36.8\%) dinyatakan meninggal (event) dan 3 penderita $(16 \%)$ dinyatakan hilang dari pengamatan.

Pada tahun ke 5 terdapat 2 penderita $(22.2 \%)$ dinyatakan hilang dan terdapat 7 penderita $(77.8 \%)$ hidup (sensor).

Berdasarkan data tersebut dapat digaris bawahi bahwa penderita meninggal tertinggi terjadi pada tahun ke 4, penderita dinyatakan hilang dari pengamatan tertinggi terjadi pada tahun ke 2, dan penderita yang bertahan hidup sampai tahun ke-5 ada 7 penderita (14.6\%). 


\section{Analisis Survival}

\section{Survival Life Berdasarkan Grading}

Tabel 4. Survival Life Penderita Kanker Payudara Berdasarkan Grading di RSUD. Dr. H. Abdul Moeloek tahun 2015-2019

\begin{tabular}{clclclc}
\hline Grading & \multicolumn{7}{c}{ Frekuensi Status Kejadian } \\
\cline { 2 - 7 } Grade 1 & Event & $\mathbf{\%}$ & Sensor & \% & Jumlah & \% \\
Grade 2 & 1 & 0 & 4 & 100 & 4 & 100 \\
Grade 3 & 9 & 5.5 & 17 & 94.4 & 18 & 100 \\
\hline Total & $\mathbf{1 0}$ & 34.6 & 17 & 65.4 & 26 & 100 \\
\hline
\end{tabular}

Tabel 4, menunjukkan gambaran survival life penderita kanker payudara tahun 2015-2019 berdasarkan grading. Dari 4 penderita kanker payudara sensor dengan grade 1 adalah $100 \%$. Dari 18 Penderita kanker payudara dengan grade 2 pada sensor adalah 94.4\% dan terjadi event adalah $5.5 \%$.
Dari 26 Penderita kanker payudara dengan sensor grade 3 adalah $65.4 \%$ dan terjadi event adalah 34.6. Berdasarkan data tersebut dapat diinterpretasikan, semakin rendah grade diagnosa kanker payudara, maka semakin tinggi survival life selama 5 tahun.

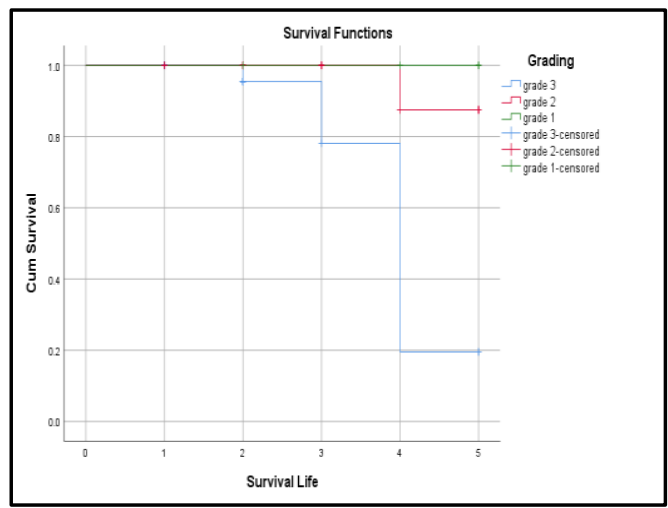

\section{Gambar 1. Menjelaskan Kelangsungan Hidup Penderita Kanker Payudara Berdasarkan Grading.}

Grade 1 dengan cum survival 1.0 yang berarti survival life selama 5 tahun penderita kanker payudara grade 1 adalah $100 \%$. Grade 2 mengalami penurunan cum survival 0.89 (89\%) dan pada tahun ke 4 mulai terjadi penurunan (meninggal). Grade 3 memiliki kelangsungan hidup paling rendah dimana kelangsungan hidup pada grade 3 lebih banyak terjadi event (meninggal) dari tahun 2 hingga tahun ke 5 dengan nilai akhir survival life pada $0.2(20 \%)$.

\section{Survival life berdasarkan Kemoterapi}

Tabel 5. Survival Life Penderita Kanker Payudara Berdasarkan di RSUD. Dr.H. Abdul Moeloek Tahun 2015-2019

\begin{tabular}{clllclc}
\hline Kemoterapi & \multicolumn{5}{c}{ Frekuensi Status Kejadian } \\
\cline { 2 - 7 } & Event & \% & Sensor & \% & Jumlah & \% \\
\hline Kemoterapi & 7 & 20 & 10 & 80 & 35 & 100 \\
Tdk Kemoterapi & 3 & 23 & 28 & 76,9 & 13 & 100 \\
\hline Total & $\mathbf{1 0}$ & & $\mathbf{3 8}$ & & $\mathbf{4 8}$ & \\
\hline
\end{tabular}


Tabel 5, menunjukkan kelangsungan hidup (survival life) penderita kanker payudara yang terdiagnosa pada tahun 2015. dari 35 penderita yang menjalani sensor kemoterapi $80 \%$ dan event adalah $20 \%$. Sementara dari 13 penderita yang tidak menjalani kemoterapi untuk kelangsungan hidup 76,9\% untuk event $23 \%$.

\section{Gambar 2. Grafik Survival Life Penderita Kanker Payudara Berdasarkan Kemoterapi}

\begin{abstract}
Berdasarkan gambar 2, cum sedangkan penderita yang tidak survival penderita yang menjalani menjalani kemoterapi cum survivalnya kemoterapi $65 \%$ dan didapat penurunan 0.0 dan didapat penurunan karena karena kematian mulai tahun ke 4

kematian pada tahun ke 2 dan 3.
\end{abstract}

\section{PEMBAHASAN}

\section{Grading}

Kanker payudara menggunakan kriteria Nottingham (Modifikasi ElstonEllis dari sistem, Scarff-Bloom Richardson) yang merupakan skala penilaian dalam gambaran sel berupa skala grade 1, 2 dan 3 (Sjamsuhidajat dan Jong, 2017).

Pada kanker payudara grade 1 sel kanker berdiferensiasi baik dan sel tidak tumbuh dengan cepat serta tidak menyebar dibandingkan dengan grade 2 dan grade 3 yang memiliki sel berdiferensiasi lebih buruk serta tumbuh cepat dan menyebar (Canadian Breast Cancer, 2020).

Hasil penelitian ini mendapatkan data penderita kanker payudara terdistribusi dari grade 1, 2 dan 3. Terbanyak pada grade $3(54.2 \%)$ dan terendah pada grade 1 ( $8.3 \%)$. Survival life selama 5 tahun tertinggi terjadi pada grade 1 dengan 100\%. Diikuti dengan grade 2 yang memiliki persentase survival life $89 \%$ dan pada grade 3 memiliki persentase terendah pada survival life sebesar $20 \%$. Dari gambaran tersebut dapat disimpulkan semakin rendah grading maka survival life 5 tahun semakin tinggi. Hasil penelitian ini.

$$
\text { Sejalan dengan penelitian }
$$

Megawati (2012) tentang gambaran ketahanan hidup lima tahun pasien kanker payudara berdasarkan karakteristik demografi dan faktor klinis menyatakan bahwa kelangsungan hidup paling tinggi ditemukan pada penderita kanker payudara dengan grade 1 (baik) dengan persentase $83.3 \%$. sedangkan pada ketahanan hidup paling rendah pada grade 3 (buruk) dengan persentase $38.5 \%$.

Sama halnya dengan penelitian (Al Farisyi dan Khambri, 2018) menyatakan bahwa semakin buruk derajat diferensiasi histologi kelangsungan hidup penderita kanker payudara semakin rendah, begitupun sebaliknya bila derajat diferensiasinya baik maka semakin baik kelangsungan hidup penderita.

Adapun (Ugnat et al, 2015) menyatakan bahwa kelangsungan hidup 10 tahun berdasarkan grading menunjukan efek yang signifikan pada grade 1 berdiferensiasi baik senilai $97 \%$ sedangkan pada grade 3 yang memiliki 
diferensiasi buruk

kelangsungan hidup $74 \%$.

\section{Kemoterapi}

Kemoterapi adalah pemberian obat untuk membunuh sel kanker, yang merupakan terapi sistemik yang menyebar keseluruh tubuh agar dapat mencapai sel kanker yang sudah bermetastasis. Kanker payudara pada pasien yang melakukan kemoterapi prognosisnya lebih baik dibandingkan yang tidak melakukan kemoterapi (Sjamsuhidajat dan Jong, 2017).

Proporsi survival life berdasarkan kemoterapi pada penelitian ini dibagi atas dua kategori berupa penderita kanker payudara yang melakukan kemoterapi $(72.9 \%)$ dan tidak melakukan kemoterapi (27.1\%). Hasil penelitian menunjukan penderita kanker payudara yang melakukan kemoterapi dengan survival life lebih tinggi daripada penderita yang tidak melakukan kemoterapi.

Terkait dengan penelitian ini, menurut National Cancer Institute, 2021 penatalaksanaan kanker payudara dengan menambahkan kemoterapi pada pada penderita kanker payudara kelangsungan hidup 5 tahun meningkat 60 menjadi $88 \%$ pada kelompok yang beresiko tinggi.

Hasil penelitian ini, sejalan dengan penelitian (Rossi et al, 2015) menjelaskan bahwa kelompok kemoterapi, tingkat kelangsungan hidup secara keseluruhan pada 5 dan 10 tahun lebih tinggi dari kelompok yang tidak kemoterapi.

Menurut penelitian (Ayuza et al, 2020) dalam pengaruh overall survival dan diseases free survival pada kanker payudara usia muda di Kota Padang $(p<0,05)$ terdapat pengaruh dari pemberian kemoterapi terhadap kanker payudara usia muda di Kota Padang. Adapun dengan penelitian (Rossi et al, 2015) menjelaskan bahwa kelompok kemoterapi, tingkat kelangsungan hidup secara keseluruhan pada 5 dan 10 tahun adalah $87.6 \%$ sedangkan kelompok yang tidak kemoterapi (manfaat absolut: 6.9\%).

\section{KESIMPULAN}

Grading pada penderita kanker payudara di RSUD Dr. H. Abdoel Muluk Provinsi Lampung terbanyak pada grade $3(58.3 \%)$ dan terendah pada grade 1 $(8.3 \%)$. Survival life selama 5 tahun penderita grade 1 adalah $100 \%$, grade $89 \%$, dan grade 3 grade $20 \%$. Sehingga semakin rendah grading semakin tinggi kelangsungan hidup 5 tahun. Penderita kanker yang menjalani kemoterapi lebih banyak $(72.9 \%)$ dari pada yang tidak menjalani kemoterapi (27.1\%).

Survival life selama 5 tahun pada penderita kemoterapi $59 \%$ dan yang tidak melakukan kemoterapi $0 \%$. Jadi, survival life selama 5 tahun lebih tinggi pada penderita kanker payudara yang melakukan kemoterapi.

\section{SARAN}

Bagi rumah sakit RSUD Dr.H. Abdul Moeloek lampung disarankan untuk melakukan pencatatan ganda berupa paper based dan paper least based dan mencantumkan alamat lengkap. Tenaga kesehatan memberikan motivasi kepada penderita kanker payudara untuk melakukan kemoterapi.

Bagi masyarakat meningkatkan dukungan dari keluarga dan orang terdekat penderita untuk melakukan pengobatan kemoterapi.

Bagi penelitian selanjutnya perlu dilakukan penelitian lanjutan dengan desain studi kohort untuk mengetahui faktor-faktor yang paling berpengaruh dalam kelangsungan hidup penderita kanker payudara.

\section{DAFTAR PUSTAKA}

Al Farisyi, M. dan Khambri, D. (2018). Analisis Survival Pasien Kanker Payudara Usia Muda di RSUP DR. M. Djamil Padang Tahun 20082017. Jurnal Kesehatan Andalas 7(4): $25 . \quad$ doi: 10.25077/jka.v7i0.917.

Ayuza, M. Harahap, W.A., Rustam, R. Dan Nindrea, R.D. (2020). Faktor yang Berpengaruh Terhadap Disease Free Survival dan Overall Survival pada Pasien Kanker Payudara Usia Muda di Kota Padang Tahun 2008 - 2018. 
Jurnal Kesehatan Andalas 9(1): 65-73 Doi: 10.25077 /jka .v9i1s .1157 .

Canadian Cancer Society. (2021). Grades of Breast Cancer. Diakses pada tanggal 16 November 2021 dari https ://www.cancer.ca/en /cancerinformation/cancertype/b reast/grading

Juwita, D. A., Almahdy dan Afdhila, R. (2018). Pengaruh Kemoterapi Terhadap Health Related Quality of Life (HRQoL) Pasien Kanker Payudara. Universitas Andalas. [Skripsi]. Padang: Universitas Andalas.

Kemenkes RI. (2018). PNPK Payudara. Kementerian Kesehatan Republik Indonesia. di akses 25 November 2020.

Megawati.

(2012). Gambaran

Ketahanan Hidup Lima Tahun

Pasien Kanker Payudara

Berdasarkan Karakteristik

Demografi dan Faktor Klinis di

Rumah Sakit Cipto

Mangunkusumo Tahun 20072010. [Skripsi]. Depok: Fakultas Kesehatan Masyarakat Universitas Indonesia.

National Cancer Institute (NCI). (2021). Breast Cancer Treatment ( PDQ (B) ) Health Professional Version. National Institutes of Health. Available at: cancer.gov/types/breast/hp/brea st-treatment-pdq.

Penelitian dan Pengembangan Kesehatan RI (2018) Laporan Riskesdas 2018, RISKESDAS $2018 . \quad$ doi: 10.1017/CBO9781107415324.00 4.

Rossi, L., Stevens, D., Pierga, J-Y., Lerebours, F., Reyal, F., Robain, M., et al. (2015). Impact of Adjuvant Chemotherapy on Breast Cancer Survival: A RealWorld Population. PLOS ONE 10(7): 1-13. doi: 10.1371 /journal.pone. 0132853

Sjamsuhidajat dan Jong, D. (2017). Buku Ajar IImu Bedah Edisi 4 Vol. 1. IV. Jakarta: EGC.
Ugnat, A. M., Xie, L., Morriss, J., Semenciw, R., and Mao, Y. (2015). Survival of Women With Breast Cancer in Ottawa, Canada: Variation With Age, Stage, Histology, Grade and Treatment. British Journal of Cancer 90(6): 1138-1143. doi: $10.1038 /$ sj.bjc. 6601662 .

World Health Organization. (2020) Indonesia Source GLOBOCAN 2018, International Agency for Research on Cancer. Available at: http://gco.iarc.frl. 